\title{
Collaborative work on evaluation of ovarian toxicity 2) Two- or four-week repeated dose studies and fertility study of mifepristone in female rats
}

\author{
Toru Tamura, Ryohei Yokoi, Yuji Okuhara, Chiho Harada, Yukari Terashima, \\ Morimichi Hayashi, Tatsuya Nagasawa, Tomoya Onozato, Kazuo Kobayashi, \\ Junji Kuroda and Hiroshi Kusama \\ Toxicology Research Laboratory, R\&D, Kissei Pharmaceutical Co., Ltd., 2320-1 Maki, Hotaka, Azumino, \\ Nagano 399-8305, Japan
}

(Received December 10, 2008)

\begin{abstract}
In order to assess ovarian pathological changes and their relationship to changes in female fertility parameters, mifepristone, a progesterone receptor antagonist, was selected as the test article and was administered orally to female rats at dose levels of $0,0.8,4,20$ and $100 \mathrm{mg} / \mathrm{kg}$ for 2 or 4 weeks in repeated dose-toxicity studies and in a female fertility study at dose levels of $0,0.8,4$ and $20 \mathrm{mg} / \mathrm{kg}$ from $>2$ weeks before copulation to postcoital day 7 . In the repeated dose toxicity studies, persistent estrus was seen in the vaginal smears, and multiple cysts in the ovaries at necropsy, increases in luteinized cysts and hypertrophy of previously formed corpora lutea were observed in the histopathological examination of ovaries in rats receiving $20 \mathrm{mg} / \mathrm{kg}$ or more for 2 or 4 weeks. In female fertility studies, persistent vaginal cornification was also observed at $20 \mathrm{mg} / \mathrm{kg}$ and the precoital interval was significantly shortened. All of the animals were completely infertile when dosed with $20 \mathrm{mg} / \mathrm{kg}$ during the post-coital period. An increase in pre-implantation losses was observed in the animals treated with $20 \mathrm{mg} / \mathrm{kg}$ during the pre-coital phase, while treatment with $4 \mathrm{mg} / \mathrm{kg}$ mifepristone during the post-coital phase induced an increase in post-implantation losses. These results suggested that a 2-week administration period would be sufficient to detect the ovarian toxicity of mifepristone in repeated dose toxicity study and the pathological findings in the ovaries would reflect the alterations in female reproductive endpoints in the female fertility study.
\end{abstract}

Key words: Mifepristone, Ovarian toxicity, Reproductive toxicity, Rat

\section{INTRODUCTION}

As part of collaborative study on toxicity related to female fertility, we performed experiments using mifepristone, a progesterone receptor antagonist which inhibits ovulation and embryonic implantation (GemzellDanielsson et al., 2004).

In the current ICH Harmonized Tripartite Guideline, the Guideline "Timing of Non-clinical Safety studies for conduct of Human Clinical Trials for Pharmaceuticals (M3(R1))" reached Step 4 on July 1997 and was amended in November 2000. However, there are regional differences in timing of reproduction toxicity studies to support the inclusion of women of childbearing potential (WOCBP) in clinical trials. In the EU, assessment of embryo-fetal development should be completed prior to Phase I trials in WOCBP and female fertility studies prior to the Phase
III trials. In the US, WOCBP may be included in early, carefully monitored clinical studies without reproduction toxicity studies as long as steps are taken to minimize the risk of pregnancy while assessment of female fertility and embryo-fetal development should be completed before WOCBP using birth control are enrolled in Phase III trials. In contrast, assessment of female fertility and embryo-fetal development should be completed prior to inclusion of WOCBP using birth control in any type of clinical trial in Japan, because the current repeated-dose toxicity studies have been considered inadequate for evaluating female reproductive function. Accordingly, the present studies were performed as a part of the series of validation studies organized by the Japanese Pharmaceuticals Manufacturing Association (JPMA) and National Institute of Health Sciences (NIHS) to evaluate whether a 2 -week testing period is adequate to detect ovarian

Correspondence: Toru Tamura (E-mail: toru_tamura@pharm.kissei.co.jp) 
toxicity and whether precise histopathological examination of female reproductive organs could be a good tool to assess female reproductive function.

It has been reported that mifepristone, selected as a test article, induced ovulatory failure and fertility impairment in rats due to its progesterone antagonistic property (van der Schoot et al., 1987; Sánchez-Criado et al., 1996; Telleria et al., 1997). The present study was designed to determine whether a 2- or 4- week administration period is sufficient for detecting histopathological changes in a repeated-dose toxicity study to compare potential ovarian toxicity with female reproductive function in a fertility study.

\section{MATERIALS AND METHODS}

\section{Test article}

Mifepristone (11beta-(4-(Dimethylamino)phenyl)17beta-hydroxy-17-(1-propynyl)estra-4,9- dien-3-one) was purchased from Tokyo Chemical Industry Co., Ltd. (Tokyo, Japan). Carboxymethylcellulose (CMC) was purchased from Wako Pure Chemical Industries, Ltd. (Osaka, Japan). Autoclaved aqueous $0.25 \%$ CMC was used as the vehicle for preparation of the test formulation. Mifepristone was suspended in the vehicle in a volume of $5 \mathrm{ml} / \mathrm{kg}$ body weight. The test formulation was prepared once weekly.

\section{Animals}

Eight-week-old specific pathogen-free (SPF) Crl: $\mathrm{CD}(\mathrm{SD})$ male rats and 5- or 8-week-old SPF Crl:CD(SD) female rats were obtained from Charles River Japan Inc. (Shiga, Japan) and maintained in a barrier system animal room controlled at a room temperature of $23 \pm 2^{\circ} \mathrm{C}$, relative humidity of $60 \pm 10 \%$, and 12-hr light/dark cycle (light on 8:00 a.m. to 8:00 p.m.) with ventilation at 13.4 times per hour. The animals were housed individually in stainless steel cages with wire-mesh bottoms $(260 \mathrm{x} 230 \mathrm{x}$ $180 \mathrm{~mm}$ ) and allowed free access to tap water and a pelleted diet (CE-2, CLEA Japan Inc., Tokyo, Japan) during the quarantine, acclimation and study periods. The animal experiments complied with the Guide to the Care and Use of Experimental Animals of the Toxicology Research Laboratory, Kissei Pharmaceutical Co., Ltd..

\section{Repeated dose toxicity studies}

After a ten-day quarantine and acclimatization period, a total of 100 animals without any abnormalities as clinical signs or in their bodyweight gain and estrous cycle were allocated into 5 groups consisting of 20 rats each using a stratified randomization method. Animals in groups 2, 3,
4 and 5 received daily administration of mifepristone by gavage at doses of $0.8,4,20$ and $100 \mathrm{mg} / \mathrm{kg}$, respectively. Animals in group 1 were administered the vehicle only. During the administration period, any clinical signs were recorded daily and measurement of the body weights was done twice a week and food consumptions once a week for all animals. Vaginal smears from all animals were obtained in the morning hours during the administration period and on the day of sacrifice. Ten rats each from all groups were sacrificed on the day following the $14^{\text {th }}$ day of treatment and the remaining animals were sacrificed on the day following the $28^{\text {th }}$ day of treatment. At sacrifice, the final body weights were measured for all animals that were then euthanized by exsanguination from the abdominal aorta under isoflurane inhalation anesthesia.

At necropsy, the following organs were weighed: thymus, spleen, liver, kidneys, adrenals, ovaries (left, right), uterus, pituitary and thyroid glands (including parathyroid glands). The pituitary and thyroid glands were weighed after being fixed in $10 \%$ phosphate-buffered formalin. The relative organ weights were calculated on the basis of the final body weights measured prior to sacrifice. After macroscopic observation, almost all organs/ tissues were fixed in 10\% phosphate-buffered formalin. Both ovaries from all animals were transversely transected to provide the maximum area of the ovary for visualization using light microscopy, and embedded in paraffin wax, sectioned at 4-5 $\mu \mathrm{m}$ and stained with hematoxylin and eosin (HE) for histopathological examination. Immunohistochemistry for proliferating cell nuclear antigen (PCNA) was also performed on serial sections of the ovaries after microwave heating in citrate buffer $(\mathrm{pH}$ 6.0) for 15 min with a mouse monoclonal antibody (DAKO JAPAN Co., Ltd., Tokyo, Japan) at a dilution of 1:800, a biotinylated secondary antibody and by avidin-biotin peroxidase complex (ABC) method with 3,3'-diaminobenzidine (DAB) as the chromogen. HE stained sections of the uterus, vagina, pituitary, adrenal glands, mammary gland, thyroid glands, liver, kidney, thymus and spleen were also prepared using routine procedures, and histopathological examination was performed on these preparations.

\section{Female fertility study}

Mifepristone was administered orally to female rats at dose levels of $0,0.8,4$ and $20 \mathrm{mg} / \mathrm{kg}$ for 2 weeks before mating. The experimental design is shown in Fig. 1. After 2-weeks administration, females were cohabited with untreated males for up to 2 weeks. Daily dosing of mifepristone or vehicle was continued through the mating period and until gestation day 7 or postcoitum day 7 . Successful copulation was defined by the presence of a vag- 
Ovarian toxicity studies of mifepristone in female rats

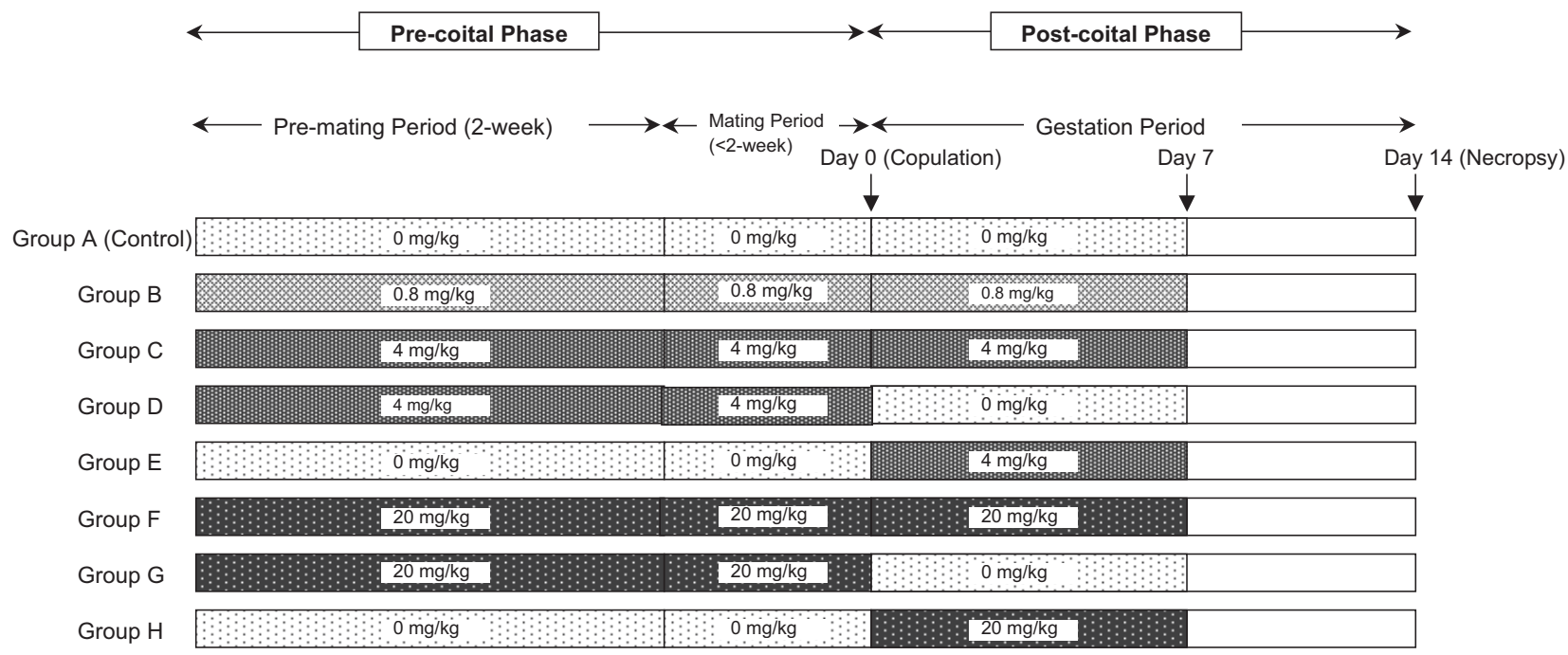

Fig. 1. Experimental design of female fertility study.

inal plug or of sperm in a vaginal smear on the morning after mating, with this day being designated as gestation day 0 or postcoitum day 0 . Groups A, B, C and F were treated with $0,0.8,4$ and $20 \mathrm{mg} / \mathrm{kg}$ mifepristone, respectively, both in the pre- and post-coital phases. Groups D and $G$ were treated with mifepristone at doses of 4 and 20 in pre-coital phase, respectively. Groups E and H were treated with 4 and $20 \mathrm{mg} / \mathrm{kg}$, respectively, in post-coital phase. Female rats were euthanized by carbon dioxide asphyxiation on gestation day 14 (pregnant) or on postcoitum day 14 (non-pregnant) or on the last day of mating period (unsuccessful copulation). At necropsy, the thoracic and intraperitoneal organs were examined macroscopically. Then the numbers of corpora lutea, implantations and live and dead embryos were counted, and copulation index and fertility index were calculated. In addition, a vaginal smear was collected daily from all females during the pre-mating period and estrous cycle evaluated. All groups consisted of 10 female animals.

\section{Statistical analysis}

For body weights, body weight gain, food consumption, hematology, clinical chemistry, absolute and relative organ weights of the animals, the numbers of corpora lutea, implantations, live embryos, length of estrous cycles and precoital intervals, and homogeneity of variation between treated groups was examined by Bartlett's test. When variation among the groups was confirmed to be homogenous, the differences between the control group and each mifepristone-treated group were examined by Dunnett's test for multiple comparisons. When varia- tion among the groups was not homogenous, a Dunnetttype rank test was performed for comparisons between the control group and each treated group. A chi-square test was used to analyze the copulation index, fertility index, and the incidence of animals with irregular estrous cycles. Pre- and post-implantation losses were determined for each litter and compared by Wilcoxon's rank-sum test. For each test differences were considered statistically significant at $\mathrm{P}<0.05$.

\section{RESULTS}

\section{Repeated dose toxicity studies}

Neither mortality nor noteworthy clinical signs were observed in any group in both the 2- and 4-week studies (Tables 1 and 2). No treatment-related changes in body weight gain, food consumption and terminal body weights were observed in either 2- or 4-week studies. In investigation of the estrous cycle using vaginal smears, an increase in number of animals with irregular estrous cycles was observed in the groups given $20 \mathrm{mg} / \mathrm{kg}$ and above for 2 and 4 weeks and therefore the mean length of the estrous cycles in the groups could not be calculated.

In organ weights, significant increases in absolute and/ or relative weights of the ovaries were observed in the groups given $20 \mathrm{mg} / \mathrm{kg}$ and above in the 2-week study and in the group given $100 \mathrm{mg} / \mathrm{kg}$ in the 4-week study (Tables 3 and 4). The absolute and/or relative pituitary weights were significantly increased in the groups given $20 \mathrm{mg} / \mathrm{kg}$ and above in both the 2- and 4-week studies. The relative weights of the adrenal glands were sig- 
Table 1. Summary of clinical observations in 2-week study

\begin{tabular}{lccccc}
\hline Dose $(\mathrm{mg} / \mathrm{kg})$ & 0 & 0.8 & 4 & 20 & 100 \\
\hline No. of animals survived & 10 & 10 & 10 & 10 & 10 \\
No. of animals died & 0 & 0 & 0 & 0 & 0 \\
Clinical signs & - & - & - & - & - \\
Body weight (g): Day 15 & $223.4 \pm 21.3$ 1) & $224.4 \pm 25.1$ & $219.4 \pm 26.2$ & $201.4 \pm 17.3$ & $220.3 \pm 19.8$ \\
Body weight gain (g/14 days) & $37.5 \pm 12.4$ & $37.7 \pm 14.6$ & $34.6 \pm 15.6$ & $20.5 \pm 11.9^{*}$ & $39.0 \pm 9.0$ \\
Food consumption (g/day/animal): Day 13 & $20.1 \pm 2.6$ & $20.7 \pm 3.0$ & $20.0 \pm 2.9$ & $16.3 \pm 2.1^{*}$ & $19.0 \pm 2.7$ \\
Mean estrous cycle (day) & 4.5 & 4.2 & 4.0 & $\mathrm{NC}$ & $\mathrm{NC}$ \\
No. of irregular estrous cycle ${ }^{2)}$ & $2 / 10$ & $1 / 10$ & $0 / 10$ & $7 / 10$ & $9 / 10$ \\
\hline
\end{tabular}

1) Mean \pm S.D.

2) Less than 4 or more than 5 days of the length of the estrous cycles, or three or more consecutive days of estrus.

-: No noteworthy findings, *: $\mathrm{p}<0.05$, NC: Not calculable because several animals showed persistent estrus.

Table 2. Summary of clinical observations in 4-week study

\begin{tabular}{lccccc}
\hline Dose $(\mathrm{mg} / \mathrm{kg})$ & 0 & 0.8 & 4 & 20 & 100 \\
\hline No. of animals survived & 10 & 10 & 10 & 10 & 10 \\
No. of animals died & 0 & 0 & 0 & 0 & 0 \\
Clinical signs & - & - & - & - & - \\
Body weight (g): Day 29 & $247.0 \pm 25.31)$ & $241.0 \pm 23.8$ & $234.3 \pm 17.2$ & $228.0 \pm 21.5$ & $243.8 \pm 19.2$ \\
Body weight gain (g/28 days) & $65.4 \pm 16.9$ & $62.0 \pm 19.6$ & $52.3 \pm 11.3$ & $48.0 \pm 14.2$ & $62.5 \pm 15.2$ \\
Food consumption (g/day/animal): Day 27 & $19.2 \pm 2.3$ & $20.6 \pm 2.4$ & $18.2 \pm 3.3$ & $18.9 \pm 2.5$ & $21.1 \pm 1.9$ \\
Mean estrous cycle (day) & 4.5 & 4.2 & 4.0 & $\mathrm{NC}$ & $\mathrm{NC}$ \\
No. of irregular estrous cycle ${ }^{2)}$ & $0 / 10$ & $1 / 10$ & $2 / 10$ & $9 / 10$ & $10 / 10$ \\
\hline
\end{tabular}

1) Mean \pm S.D.

2) Less than 4 or more than 5 days of estrous, or three or more consecutive days of estrus.

-: No noteworthy findings, NC: Not calculable because several animals showed persistent estrus.

nificantly increased in the groups given $100 \mathrm{mg} / \mathrm{kg}$ in the 4-week study. The absolute and relative thyroid weights were significantly increased in groups given $100 \mathrm{mg} /$ $\mathrm{kg}$ in the 4-week study. The absolute and/or relative liver weights were significantly increased in the group given $100 \mathrm{mg} / \mathrm{kg}$ in both 2- and 4-week studies. No significant intergroup difference in weight of uterus between the control group and the groups given test article was seen in either of the 2- or 4-week studies.

At necropsy, multiple cysts in the ovaries were observed in rats receiving $20 \mathrm{mg} / \mathrm{kg}$ and above in both the 2- and 4-week studies. On histopathology, treatmentrelated findings were observed in the ovaries, pituitary, mammary gland, adrenal glands, thyroid gland and liver (Tables 5 and 6). In the ovaries, increases in luteinized cysts, whose size was markedly larger than those of the Graafian follicles were observed in rats receiving $20 \mathrm{mg} /$ $\mathrm{kg}$ and above in both 2- and 4-week studies. In addition, increase in unruptured luteinized follicles partially lined by vascularized and luteinized granulosa cell layer and occasionally containing an unovulated oocyte were also observed in several animals receiving $100 \mathrm{mg} / \mathrm{kg}$ in the 2week study and in the $20 \mathrm{mg} / \mathrm{kg}$ and above in the 4-week study. (Figs. 2a-c). Loss of newly or currently formed corpora lutea and hypertrophy of previously formed corpora lutea were also observed in rats receiving $20 \mathrm{mg} / \mathrm{kg}$ and above in both the 2- and 4-week studies (Fig. 2d). An increase in large atretic follicles, whose size corresponded to a type 8 follicles (Pedersen and Peters, 1968), were observed in a few animals in the group given $20 \mathrm{mg} / \mathrm{kg}$ in the 2- and 4-week studies and in several animals in the groups given $100 \mathrm{mg} / \mathrm{kg}$ in both the 2- and 4-week studies. No abnormalities were observed in small and medium follicles (Pedersen and Peters, 1968) that were easily 
Ovarian toxicity studies of mifepristone in female rats

Table 3. Summary of organ weights in 2-week study

\begin{tabular}{lcccccc}
\hline Dose (mg/kg) & & 0 & 0.8 & 4 & 20 & 100 \\
\hline No. of animals measured & & 10 & 10 & 10 & 10 & 10 \\
Ovary (Right) & Abs. & $0.045 \pm 0.008$ & $0.050 \pm 0.014$ & $0.048 \pm 0.009$ & $0.059 \pm 0.057^{*}$ & $0.057 \pm 0.010$ \\
& Rel. & $0.201 \pm 0.030$ & $0.222 \pm 0.041$ & $0.225 \pm 0.058$ & $0.293 \pm 0.078^{* *}$ & $0.260 \pm 0.040^{*}$ \\
Ovary (Left) & Abs. & $0.049 \pm 0.011$ & $0.048 \pm 0.005$ & $0.049 \pm 0.011$ & $0.062 \pm 0.018$ & $0.059 \pm 0.015$ \\
& Rel. & $0.221 \pm 0.047$ & $0.213 \pm 0.027$ & $0.227 \pm 0.051$ & $0.309 \pm 0.093^{*}$ & $0.269 \pm 0.072$ \\
Pituitary & Abs. & $0.014 \pm 0.001$ & $0.014 \pm 0.003$ & $0.015 \pm 0.003$ & $0.017 \pm 0.004^{*}$ & $0.017 \pm 0.002$ \\
& Rel. & $0.062 \pm 0.006$ & $0.061 \pm 0.012$ & $0.066 \pm 0.007$ & $0.084 \pm 0.016^{* *}$ & $0.075 \pm 0.008^{*}$ \\
Uterus & Abs. & $0.580 \pm 0.187$ & $0.501 \pm 0.165$ & $0.538 \pm 0.147$ & $0.481 \pm 0.116$ & $0.519 \pm 0.139$ \\
& Rel. & $2.634 \pm 0.953$ & $2.228 \pm 0.646$ & $2.471 \pm 0.676$ & $2.410 \pm 0.621$ & $2.357 \pm 0.607$ \\
Adrenal gland & Abs. & $0.081 \pm 0.011$ & $0.077 \pm 0.009$ & $0.078 \pm 0.011$ & $0.072 \pm 0.011$ & $0.091 \pm 0.014$ \\
& Rel. & $0.362 \pm 0.041$ & $0.345 \pm 0.040$ & $0.360 \pm 0.061$ & $0.357 \pm 0.051$ & $0.414 \pm 0.049$ \\
Thyroid gland & Abs. & $0.020 \pm 0.004$ & $0.020 \pm 0.005$ & $0.018 \pm 0.003$ & $0.020 \pm 0.003$ & $0.022 \pm 0.002$ \\
& Rel. & $0.088 \pm 0.017$ & $0.087 \pm 0.020$ & $0.082 \pm 0.017$ & $0.099 \pm 0.016$ & $0.102 \pm 0.013$ \\
Liver & Abs & $9.53 \pm 1.42$ & $9.62 \pm 1.54$ & $9.61 \pm 1.69$ & $8.83 \pm 1.20$ & $10.94 \pm 1.41$ \\
& Rel. & $42.50 \pm 2.99$ & $42.70 \pm 2.34$ & $43.56 \pm 2.89$ & $43.72 \pm 2.83$ & $49.56 \pm 3.15 * *$ \\
\hline
\end{tabular}

1) Mean \pm S.D.

Abs.: Absolute weight, Rel.: Relative weight to body weight $(\mathrm{kg}),{ }^{*}: \mathrm{p}<0.05,{ }^{* *}$ : $\mathrm{p}<0.01$

Table 4. Summary of organ weights in 4-week study

\begin{tabular}{lcccccc}
\hline Dose (mg/kg) & & 0 & 0.8 & 4 & 20 & 100 \\
\hline No. of animals measured & & 10 & 10 & 10 & 10 & 10 \\
Ovary (Right) & Abs. & $0.051 \pm 0.006^{1)}$ & $0.050 \pm 0.008$ & $0.051 \pm 0.005$ & $0.057 \pm 0.013$ & $0.093 \pm 0.034^{* *}$ \\
& Rel. & $0.210 \pm 0.030$ & $0.209 \pm 0.037$ & $0.219 \pm 0.024$ & $0.252 \pm 0.052$ & $0.382 \pm 0.138^{* *}$ \\
Ovary (Left) & Abs. & $0.053 \pm 0.007$ & $0.052 \pm 0.007$ & $0.050 \pm 0.008$ & $0.055 \pm 0.018$ & $0.076 \pm 0.015^{*}$ \\
& Rel. & $0.216 \pm 0.035$ & $0.217 \pm 0.031$ & $0.212 \pm 0.029$ & $0.243 \pm 0.071$ & $0.316 \pm 0.073^{* *}$ \\
Pituitary & Abs. & $0.013 \pm 0.002$ & $0.014 \pm 0.002$ & $0.014 \pm 0.002$ & $0.017 \pm 0.004$ & $0.025 \pm 0.007$ \\
& Rel. & $0.054 \pm 0.009$ & $0.057 \pm 0.007$ & $0.061 \pm 0.008$ & $0.074 \pm 0.013^{* *}$ & $0.101 \pm 0.026^{* *}$ \\
Uterus & Abs. & $0.534 \pm 0.123$ & $0.584 \pm 0.142$ & $0.515 \pm 0.192$ & $0.569 \pm 0.189$ & $0.537 \pm 0.061$ \\
& Rel. & $2.183 \pm 0.540$ & $2.449 \pm 0.641$ & $2.232 \pm 0.978$ & $2.526 \pm 0.888$ & $2.207 \pm 0.206$ \\
Adrenal gland & Abs. & $0.085 \pm 0.007$ & $0.081 \pm 0.013$ & $0.079 \pm 0.010$ & $0.081 \pm 0.015$ & $0.105 \pm 0.020$ \\
& Rel. & $0.350 \pm 0.057$ & $0.343 \pm 0.080$ & $0.337 \pm 0.040$ & $0.359 \pm 0.070$ & $0.432 \pm 0.078^{*}$ \\
Thyroid gland & Abs. & $0.018 \pm 0.004$ & $0.017 \pm 0.002$ & $0.017 \pm 0.002$ & $0.018 \pm 0.002$ & $0.022 \pm 0.003^{* *}$ \\
& Rel. & $0.072 \pm 0.014$ & $0.072 \pm 0.013$ & $0.074 \pm 0.009$ & $0.081 \pm 0.012$ & $0.089 \pm 0.012^{*}$ \\
Liver & Abs & $9.78 \pm 1.47$ & $9.30 \pm 1.55$ & $9.37 \pm 1.23$ & $9.12 \pm 1.40$ & $12.26 \pm 1.26^{* *}$ \\
& Rel. & $39.43 \pm 2.42$ & $38.45 \pm 3.58$ & $39.89 \pm 3.28$ & $39.90 \pm 3.76$ & $50.24 \pm 2.97^{* *}$ \\
\hline
\end{tabular}

1) Mean \pm S.D.

Abs.: Absolute weight, Rel.: Relative weight to body weight (kg), ${ }^{*}: \mathrm{p}<0.05,{ }^{* *}$ : $\mathrm{p}<0.01$

distinguishable by PCNA immunostaining. The number of rats with cornification in the vaginal epithelium, indicating persistent estrus, was increased in the groups giv- en $100 \mathrm{mg} / \mathrm{kg}$ in the 4-week studies. Hypertrophy of the pars distalis in the pituitary was observed in 2 out of 10 animals in the group given $20 \mathrm{mg} / \mathrm{kg}$ and in 5 out of 10 
T. Tamura et al.

Table 5. Summary of gross and histopathological findings in 2 -week study

\begin{tabular}{|c|c|c|c|c|c|c|c|c|}
\hline Dose (mg/kg) & & & & 0 & 0.8 & 4 & 20 & 100 \\
\hline No. of animals survived & & & & 10 & 10 & 10 & 10 & 10 \\
\hline \multicolumn{9}{|l|}{ Gross pathology } \\
\hline Ovary & & & $\mathrm{N}$ & 10 & 10 & 10 & 10 & 10 \\
\hline Multiple cysts & & & & 0 & 0 & 0 & 2 & 3 \\
\hline Histopathology & G & & & & & & & \\
\hline Ovary\# & & & $\mathrm{N}$ & 10 & 10 & 10 & 10 & 10 \\
\hline \multirow[t]{2}{*}{ Luteinized cysts, increase } & + & $(1-5)$ & & 1 & 0 & 0 & 6 & 9 \\
\hline & ++ & $(>6)$ & & 0 & 0 & 0 & 1 & 1 \\
\hline Unruptured luteinized follicle, increase & + & $(1-5)$ & & 0 & 0 & 1 & 1 & 5 \\
\hline Atretic follicles (large), increase & + & $(>4)$ & & 0 & 0 & 0 & 1 & 3 \\
\hline Newly formed corpora lutea, loss & + & $(0)$ & & 0 & 0 & 0 & 1 & 2 \\
\hline Currently formed corpora lutea, loss & + & $(0)$ & & 0 & 0 & 0 & 3 & 5 \\
\hline Previously formed corpora lutea, hypertrophy & + & & & 0 & 0 & 0 & 4 & 4 \\
\hline Pituitary & & & $\mathrm{N}$ & 10 & 10 & 10 & 10 & 10 \\
\hline Hypertrophy, pars distalis & + & & & 0 & 0 & 0 & 2 & 5 \\
\hline Mammary gland & & & $\mathrm{N}$ & 8 & 10 & 10 & 9 & 9 \\
\hline Secretory activity, increase & + & & & 0 & 0 & 0 & 5 & 6 \\
\hline Adrenal gland & & & $\mathrm{N}$ & 10 & 10 & 10 & 10 & 10 \\
\hline Hypertrophy, cortex & + & & & 0 & 0 & 0 & 0 & 3 \\
\hline Thyroid gland & & & $\mathrm{N}$ & 10 & 10 & 10 & 10 & 10 \\
\hline Hypertrophy, follicular epithelial cell & + & & & 0 & 0 & 0 & 0 & 5 \\
\hline
\end{tabular}

G: Grade, N: Number of examined, +: slight, ++: moderate

\#: Number of cysts or follicles corresponds to findings concerned with grading is given in parentheses

animals receiving $100 \mathrm{mg} / \mathrm{kg}$ in both 2 - and 4-week studies. Mammary gland secretory activity was increased in 5 out of 9 animals in the group given $20 \mathrm{mg} / \mathrm{kg}$ and in 6 out of 9 animals in the group given $100 \mathrm{mg} / \mathrm{kg}$ in the 2 -week study. An increase in secretory activity was also observed in rats receiving $20 \mathrm{mg} / \mathrm{kg}$ and above in the 4-week study. Cortical hypertrophy in the adrenal glands and follicular epithelial cell hypertrophy in the thyroid were observed in rats receiving $100 \mathrm{mg} / \mathrm{kg}$ in both 2 - and 4-week studies. In the liver, centrilobular hepatocyte hypertrophy was observed in rats receiving $100 \mathrm{mg} / \mathrm{kg}$ in the 4-week study.

\section{Female fertility study}

There were no deaths and no treatment-related clinical signs in females in any dose group (Table 7). There were no treatment-related changes in body weights and food consumption between group A (control) and any of the mifepristone-treated groups (groups B, C, D, E, F, G and $\mathrm{H}$ ). In the female estrous cycle observations during the pre-mating period, 5 and 7 animals showed persistent vaginal cornification ( $>2$ days) in groups $\mathrm{F}$ and $\mathrm{G}$, in which period mifepristone was administered at $20 \mathrm{mg} /$ $\mathrm{kg}$. The incidence of animals with irregular estrous cycles increased in these groups. No remarkable abnormalities were detected in the estrous cycle in animals receiving 0.8 or $4 \mathrm{mg} / \mathrm{kg}$ during the pre-mating period (groups B, C and D). Successful copulation was observed in all females at all groups except for one animal in group B. However, a significant decrease in the days prior to copulation (precoital interval) was noted in groups $\mathrm{F}$ and $\mathrm{G}$. The animals treated with $20 \mathrm{mg} / \mathrm{kg}$ during postcoitum day 0 to day 7 were completely infertile (groups $\mathrm{F}$ and $\mathrm{H}$ ). At necropsy of the dams, cysts in the ovary were observed macroscopically in animals treated with $20 \mathrm{mg} / \mathrm{kg}$ in either the pre- or post-coital phases (groups F, G and H). Significant decreases in number of implantations and number of live embryos were noted in animals receiving $20 \mathrm{mg} /$ $\mathrm{kg}$ during the gestation period only (group $\mathrm{G}$ ). Related to 
Ovarian toxicity studies of mifepristone in female rats

Table 6. Summary of gross and histopathological findings in the 4-week study

\begin{tabular}{|c|c|c|c|c|c|c|c|c|}
\hline Dose $(\mathrm{mg} / \mathrm{kg})$ & & & & 0 & 0.8 & 4 & 20 & 100 \\
\hline No. of animals survived & & & & 10 & 10 & 10 & 10 & 10 \\
\hline \multicolumn{9}{|l|}{ Gross pathology } \\
\hline Ovary & & & $\mathrm{N}$ & 10 & 10 & 10 & 10 & 10 \\
\hline Multiple cysts & & & & 0 & 0 & 0 & 1 & 8 \\
\hline Histopathology & G & & & & & & & \\
\hline Ovary \# & & & $\mathrm{N}$ & 10 & 10 & 10 & 10 & 10 \\
\hline \multirow[t]{2}{*}{ Luteinized cysts, increase } & + & $(1-5)$ & & 1 & 0 & 0 & 4 & 5 \\
\hline & ++ & $(>6)$ & & 0 & 0 & 0 & 1 & 4 \\
\hline Unruptured luteinized follicle, increase & + & $(1-5)$ & & 0 & 0 & 0 & 3 & 3 \\
\hline Atretic follicle (large), increase & + & $(>4)$ & & 0 & 0 & 0 & 2 & 4 \\
\hline Newly formed corpora lutea, loss & + & $(0)$ & & 0 & 0 & 0 & 2 & 8 \\
\hline Currently formed corpus luteum, loss & + & $(0)$ & & 0 & 0 & 0 & 3 & 2 \\
\hline Previously formed corpora lutea, hypertrophy & & & & 0 & 0 & 0 & 3 & 7 \\
\hline Pituitary & & & $\mathrm{N}$ & 10 & 10 & 10 & 10 & 10 \\
\hline Hypertrophy, pars distalis & + & & & 0 & 0 & 0 & 2 & 5 \\
\hline Mammary gland & & & $\mathrm{N}$ & 10 & 10 & 10 & 10 & 10 \\
\hline Secretory activity, increase & + & & & 0 & 0 & 0 & 2 & 8 \\
\hline Adrenal gland & & & $\mathrm{N}$ & 10 & 10 & 10 & 10 & 10 \\
\hline Hypertrophy, cortex & + & & & 0 & 0 & 0 & 0 & 3 \\
\hline Thyroid gland & & & $\mathrm{N}$ & 10 & 10 & 10 & 10 & 10 \\
\hline Hypertrophy, follicular epithelial cell & + & & & 0 & 0 & 0 & 0 & 7 \\
\hline Liver & & & $\mathrm{N}$ & 10 & 10 & 10 & 10 & 10 \\
\hline Hypertrophy, hepatocyte, centrilobular & + & & & 0 & 0 & 0 & 0 & 3 \\
\hline
\end{tabular}

G: Grade, N: Number of examined, +: slight, ++: moderate, +++: severe

\#: Number of the cysts or follicles corresponds to the findings concerned with the grading is given in parentheses

these lower values, an increase in preimplantation losses was observed in this group. In the groups treated with 4 $\mathrm{mg} / \mathrm{kg}$ during the gestation period (groups $\mathrm{C}$ and $\mathrm{E}$ ), there was a significant decrease or a tendency to decrease in the number of live embryos and a significant increase in the number of dead embryos, but not the number of implantations. Related to these changes, an increase in postimplantation losses was observed in these groups, while there were no noteworthy effects on embryonic development in the group of animals treated with $4 \mathrm{mg} / \mathrm{kg}$ during pre-coital phase only (group D). No effects on embryonic development were observed in animals treated with 0.8 $\mathrm{mg} / \mathrm{kg}$ in either the pre- or post-coital phases (group B).

\section{DISCUSSION}

Mifepristone is a synthetic steroid that possesses great affinity for progesterone receptors with no agonistic activity (Bygdeman, et al., 1993). Due to its antiprogesterone activity, it was proposed that mifepristone be used for the termination of early human pregnancy (Sitruk-Ware, 2006). In animal experiments in rats, it has been reported that mifepristone treatment induced ovulatory failure, morphological changes in the reproductive and endocrine organs accompanied by hormonal fluctuation due to its progesterone- and corticosteroid antagonistic properties (van der Schoot et al., 1987; Sánchez-Criado et al., 1996).

In the present repeated-dose studies, several characteristic findings reported previously were also seen. Persistent vaginal cornifications, which indicated persistent estrus, were noted in the groups given $20 \mathrm{mg} / \mathrm{kg}$ and above in both 2- and 4-week studies. This resulted from the increased serum concentrations of estradiol in 

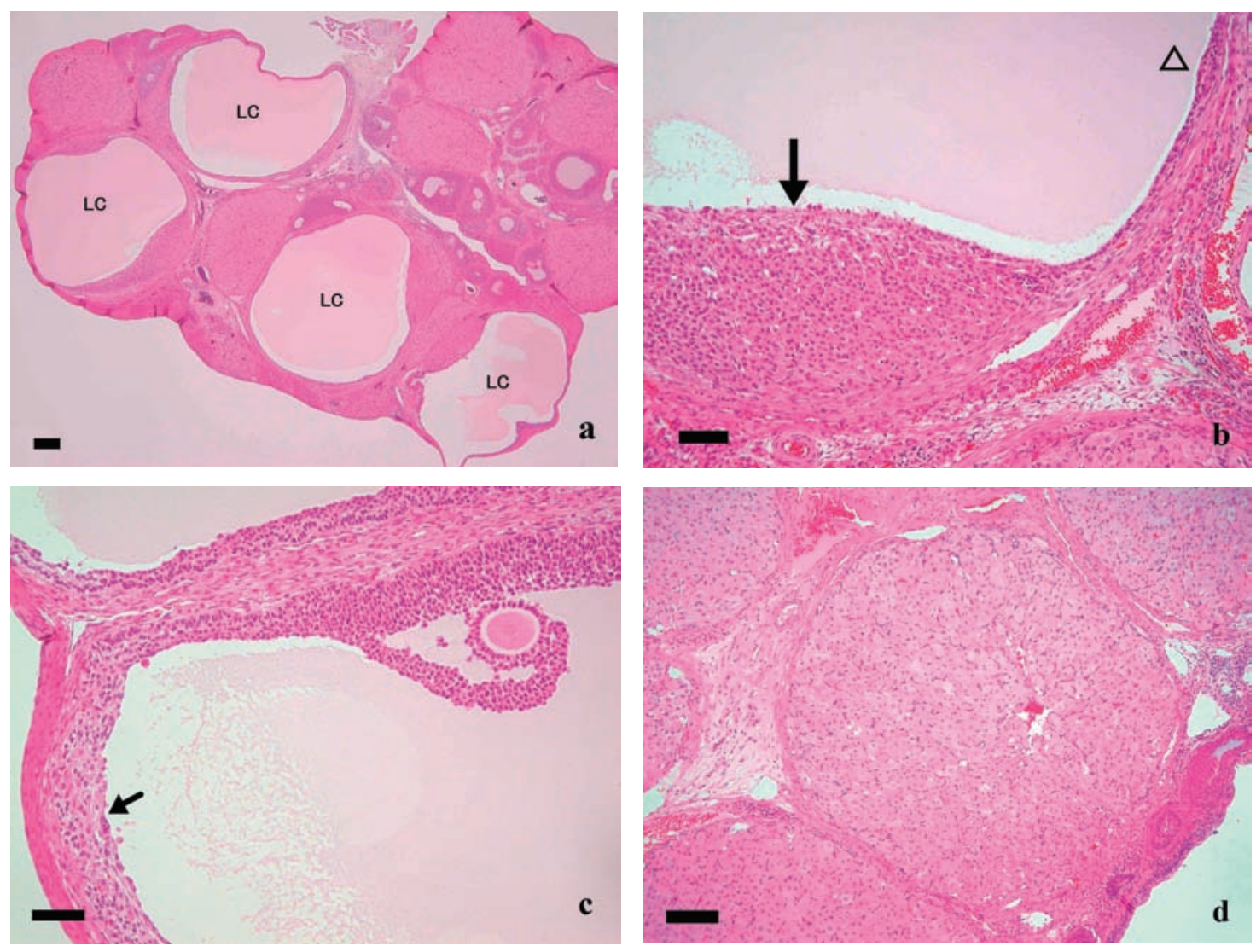

Fig. 2. Histopathological findings in the ovaries in mifepristone-treated rats receiving $20 \mathrm{mg} / \mathrm{kg}$ for 2 weeks (a, b, and c) and 100 $\mathrm{mg} / \mathrm{kg}$ for 4 weeks (d). HE stain. (a): Multiple fluid-filled luteinized cysts (LC) observed in ovary (bar $=200 \mu \mathrm{m})$. (b): Higher magnification of (a). Large cyst lined by thin (open arrowhead) and massive (arrows) luteinized cell layers (bar $=50$ $\mu \mathrm{m})$. (c): An unruptured follicle lined by vascularized and luteinized granulosa cell layer (arrow) containing an oocyte (bar $=50 \mu \mathrm{m})$. (d): Numerous hypertrophic previously formed corpora lutea without signs of structural luteolysis but no newly or currently formed corpora lutea were observed in a rat with persistent vaginal cornification $(\mathrm{bar}=100 \mu \mathrm{m})$.

the absence of the counteracting action of progesterone, caused by the progesterone antagonistic property of mifepristone (Sánchez-Criado et al., 1993). Increases in luteinized cysts and unruptured luteinized follicles occasionally containing an oocyte within the cavity were observed in the groups given $20 \mathrm{mg} / \mathrm{kg}$ and above in both 2- and 4week studies and large atretic follicles, whose size corresponded to type 8 (Pedersen and Peters, 1968) increased in the group given $100 \mathrm{mg} / \mathrm{kg}$ in the 2-week study and in the groups given $20 \mathrm{mg} / \mathrm{kg}$ and above in the 4-week study. These characteristic changes were interpreted as treatment-related ovulatory failure caused by decreased proestrus surges of luteinizing hormone (LH) and increased basal serum concentrations of LH during diestrous due to the progesterone antagonistic effect of mifepristone (Tebar et al., 1995; Sánchez-Criado et al., 1996; Telle- ria et al., 1997; Bellido et al., 1999), although measurement of the related hormone levels was not performed in this study. The lowered levels of follicle stimulating hormone (FSH) also induced by mifepristone treatment with the elevated basal level of LH may have induced the atresia of the large follicles (Bogovich, 1989). In addition, elevated prolactin secretion from the pituitary, due to sensitization by increased estradiol secretion, caused by stimulation from increases in the basal levels of $\mathrm{LH}$ (Sánchez-Criado et al., 1990), can act luteotrophically leading to anovulatory or atretic follicles. As a result, the rupture of ovulation becomes blocked and granulosa cell luteinization may occur in the ovaries. Accordingly, loss of currently formed corpora lutea and hypertrophy of previously formed corpora lutea due to elevated LH and the luteotropic activity of prolactin were also observed 
Ovarian toxicity studies of mifepristone in female rats

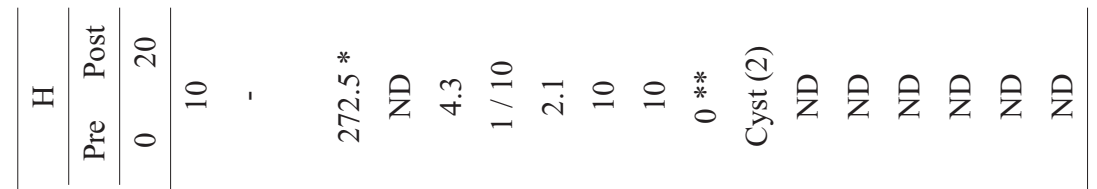

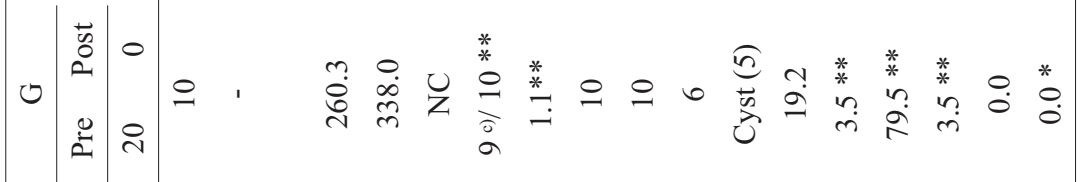

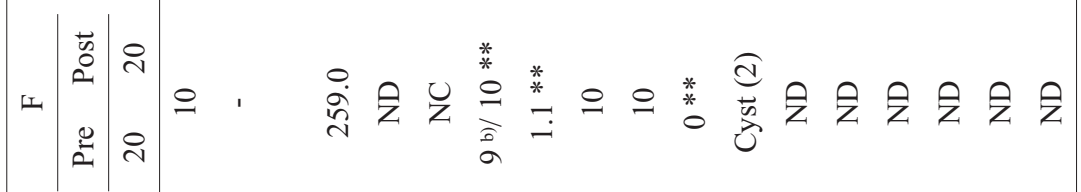

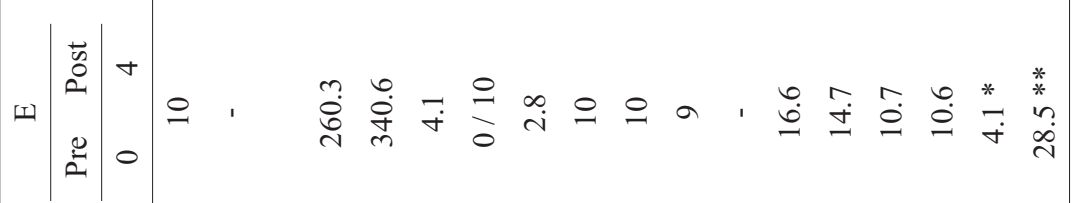

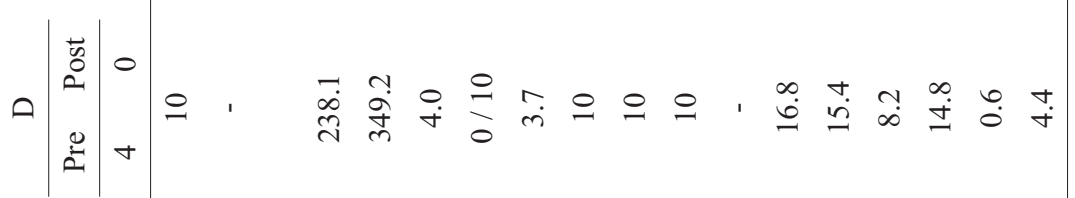

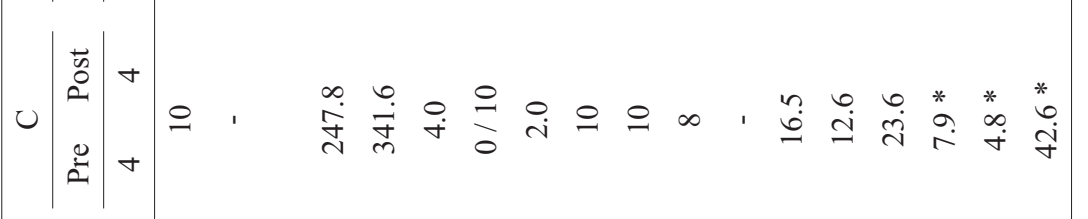

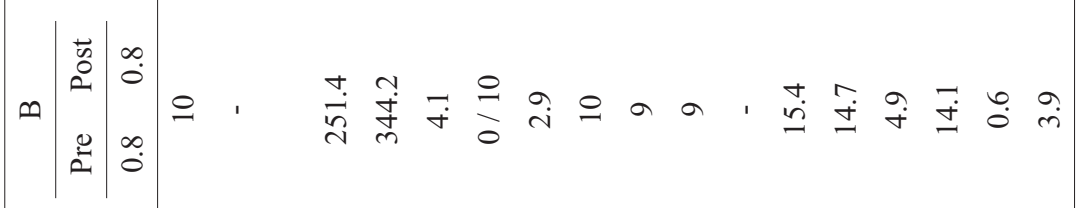

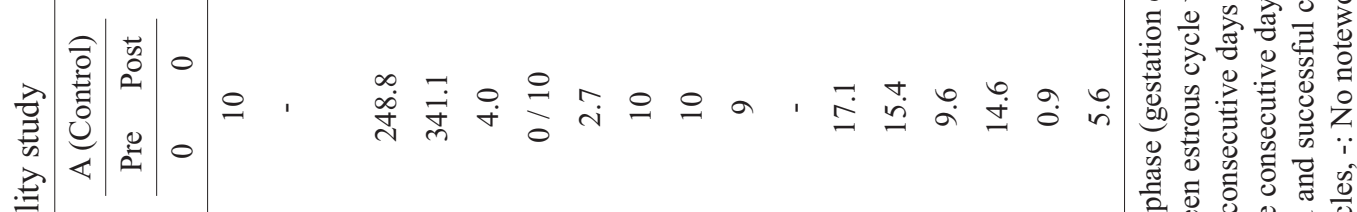

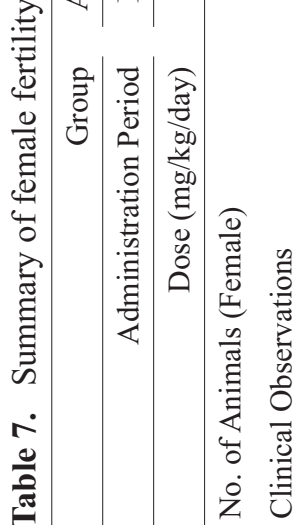

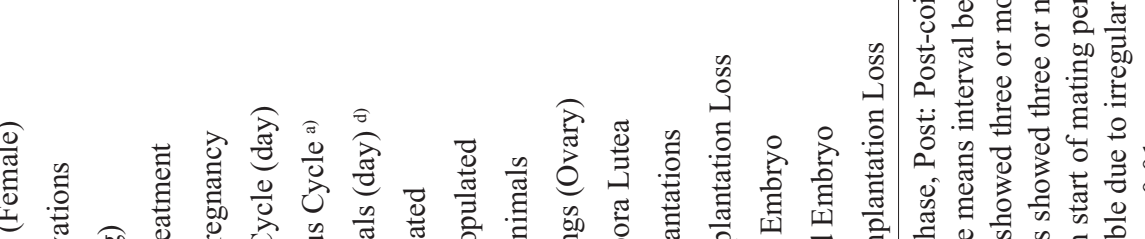

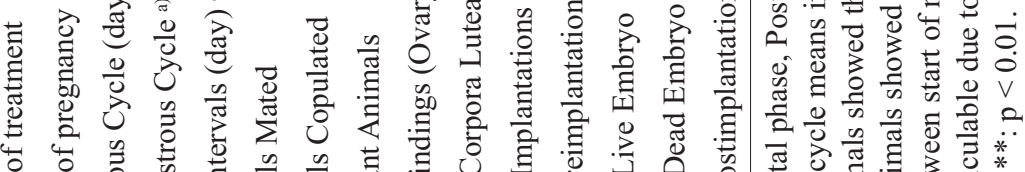

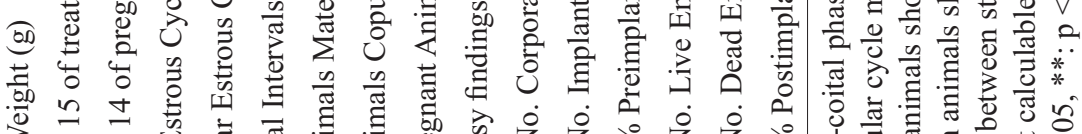

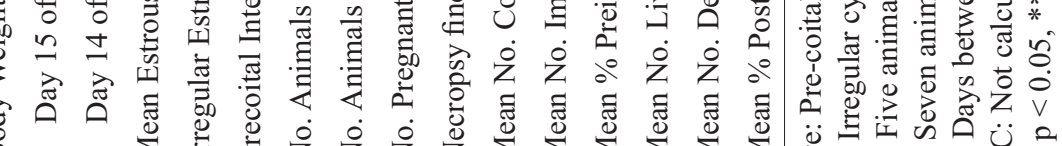

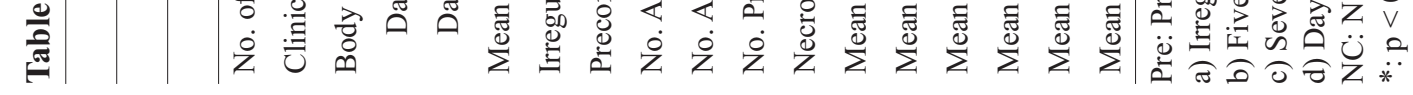


and the weight of ovaries increased in the groups given $20 \mathrm{mg} / \mathrm{kg}$ and above in both 2- and 4-week studies. These morphological changes observed in the ovaries were considered to be predictive findings for the alteration of female reproductive endpoints, including the persistent estrus, short precoital interval, and decreased numbers of implantations observed in rats receiving $20 \mathrm{mg} / \mathrm{kg}$ in the present female fertility studies. It was not clear if the unruptured luteinized follicle observed in one out of 10 rats in the group given $4 \mathrm{mg} / \mathrm{kg}$ was a treatment-related change because increased luteinized cysts, which may be incidental, were also observed in one rat each in both of the 2- and 4-week studies and no abnormalities in the ovaries were seen in the 4-week study. Therefore, the noobserved-adverse-effect level (NOAEL) for ovarian toxicity in the repeated dose toxicity study was considered to be $4 \mathrm{mg} / \mathrm{kg}$ in both of the 2- and 4-week studies.

In addition to the ovarian findings, mifepristone treatment-related changes were also observed in several organs. Hypertrophy of the pars distalis in the pituitary may be indicative of enhanced secretion of prolactin and was considered that increased secretory activity of the mammary gland was probably caused by stimulation by prolactin. In the adrenals, bilateral cortical hypertrophy characterized by increased size of the zona fasciculata and zona reticularis corresponding to the increased adrenal weights, was observed. These changes probably indicate an increase in pituitary adrenocorticotropic hormone (ACTH) secretion caused by feedback mechanisms due to a corticosteroid antagonistic effect of mifepristone (van der Schoot et al., 1987). In a previous study, it was reported that a significant increase in thyroid stimulating hormone (TSH) and a decrease in triiodothyronine (T3) and thyroxine (T4) with histopathological changes in the thyroid were induced by mifepristone treatment in rats (O'Connor et al., 2000). In the present studies, follicular cell hypertrophy in the thyroid was observed in the groups given $100 \mathrm{mg} / \mathrm{kg}$ in both of the 2- and 4-week studies, and it is possible that the increased liver weight and centrilobular hepatocytic hypertrophy could be attributable to increased catabolism of the thyroid hormones leading to thyroid stimulation. No abnormalities were observed in the uterus in this study, while several morphological changes were reported in rats after long-term treatment with progesterone antagonists (Rumpel et al., 1993).

In the female fertility study, females receiving 20 $\mathrm{mg} / \mathrm{kg}$ showed persistent vaginal cornification as was seen in the repeated-dose studies and the precoital interval at this dose shorter than that in the control. In the present study, female rats treated with $20 \mathrm{mg} / \mathrm{kg}$ mifepristone during the pre-coital phase had increases in pre- implantation losses relating to decreases in the numbers of implantations. These changes are considered to be related to suppression of follicular ovulation (Rao and Mahesh, 1986; Ledger et al., 1992; Sánchez-Criado et al., 1993; Tebar et al., 1995; Telleria et al., 1997; Reel et al., 1998) and/or to disruption of endometrial development (Croxatto et al., 1993; Gemzell-Danielsson et al., 1997). Since treatment with $4 \mathrm{mg} / \mathrm{kg}$ during the pre-coital phase had no effects on implantation in the present study, this dose level seemed to have no effects on ovulation and/or endometrial development.

In the $20 \mathrm{mg} / \mathrm{kg}$ group with treatment with mifepristone during the post-coital phase, none of the animals had conceptuses although all of them had successful copulation. It has been reported that postcoital administration of mifepristone modulates egg transport through the oviduct (Roblero, et al., 1987; Fuentealba, et al., 1987; Yang and Wu, 1990), retards early embryonic development (Psychoyos and Prapas, 1987; Roblero and Croxatto, 1991), delays endometrial maturation (Roblero and Croxatto, 1991; Batista, et al., 1992; Cameron, et al., 1996) and thereby inhibits or delays implantation (Psychoyos and Prapas, 1987; Roblero and Croxatto, 1991; Dao, et al., 1996). In the present study, treatment with $4 \mathrm{mg} / \mathrm{kg}$ mifepristone during the post-coital phase produced small numbers of live embryos and a high postimplantation embryonic mortality but did not reduce the number of implantations. Post-implantation embryonic survival showed the greatest susceptibility to mifepristone among the endpoints evaluated in that treatment with $4 \mathrm{mg} / \mathrm{kg}$ affected post-implantation development, but had no effects on ovulation and pre-implantation development, while treatment with $20 \mathrm{mg} / \mathrm{kg}$ blocked ovulation and prevented implantation as described above. Mifepristone has been shown to terminate pregnancy with embryonic death (Avrech et al., 1991; Srivastava et al., 1995; Telleria and Deis, 1996). At the dose level of $0.8 \mathrm{mg} / \mathrm{kg}$, there were no effects on early embryonic development when administered in either the pre- or post-ovulation phase. There was no systemic toxicity seen in the female rats at any dose of mifepristone. The NOAEL for general toxicity in the females, therefore, was considered to be $>20 \mathrm{mg} / \mathrm{kg}$. The NOAEL for the reproductive function and that for the early embryonic development were considered to be $4 \mathrm{mg} / \mathrm{kg}$ and $0.8 \mathrm{mg} / \mathrm{kg}$, respectively. Thus, the NOAEL for reproductive function in the pre-coital treatment phase in the female fertility study was equivalent to that for ovarian toxicity in the repeated dose toxicity studies, although the NOAEL for the development of the next generation was lower than that for ovarian toxicity in the repeated-dose toxicity studies. 
Ovarian toxicity studies of mifepristone in female rats

In the present experiment, 2- and 4-week repeated-dose toxicity studies were performed to determine the optimal administration period for detecting the morphological changes in ovaries caused by mifepristone treatment. In addition, the studies also evaluated if the ovarian morphological findings could provide predictive evidence for alterations in female fertility end points in the female fertility study caused by the test article. Based on the results of the present studies, it is considered that the morphological changes observed in the ovaries in both of the 2- and 4-week repeated dose toxicity studies could reflect alterations in the female reproductive endpoints, such as persistent estrus, short precoital interval and increased preimplantation loss, as were observed in the rats receiving $20 \mathrm{mg} / \mathrm{kg}$ during the pre-coital phase in the present female fertility study.

In conclusion, it is proposed that a 2 -week administration period is sufficient to detect the ovarian toxicity of mifepristone in the repeated-dose toxicity study and the pathological findings in the ovaries in the repeated-dose toxicity study performed with sufficiently enough dose levels would predict alterations in female reproductive function in the female fertility study.

\section{REFERENCES}

Avrech, O.M., Golan, A., Weinraub, Z., Bukovsky, I. and Caspi, E. (1991): Mifepristone (RU486) alone or in combination with a prostaglandin analogue for termination of early pregnancy: a review. Fertil. Steril., 56, 385-393.

Batista, M.C., Cartledge, T.P., Zellmer, A.W., Merino, M.J., Axiotis, C., Loriaux, D.L. and Nieman, L.K. (1992): Delayed endometrial maturation induced by daily administration of the antiprogestin RU486: a potential new contraceptive strategy. Am. J. Obstet. Gynecol., 167, 60-65.

Bellido, C., Gonzalez, D., Aguilar, R. and Sanchez-Criado, J.E. (1999): Antiprogestins RU486 and ZK299 suppress basal and LHRH-stimulated FSH and LH secretion at pituitary level in the rat in an oestrous cycle stage-dependent manner. J. Endocrinol., 163, 79-85.

Bogovich, K. (1989): Induction of ovarian cysts in progesteronesynchronized immature rats: evidence that suppression of follicular aromatase activity is not a prerequisite for the induction of cystic follicles. Endocrinology, 124, 1646-1653.

Bygdeman, M., Swahn, M.L., Gemzell-Danielsson, K. and Svalamder, P. (1993): Mode of Action of RU 486. Ann. Med., 25, 61-64.

Cameron, S.T., Critchley, H.O., Thong, K.J., Buckley, C.H., Williams, A.R. and Barird, D.T. (1996): Effects of daily low dose mifepristone on endometrial maturation and proliferation. Hum. Reprod., 11, 2518-2526.

Croxatto, H.B., Salvatierra, A.M., Croxatto, H.D. and Fuentealba, B. (1993): Effects of continuous treatment with low dose mifepristone throughout one menstrual cycle. Hum. Reprod., 8, 201207.

Dao, B., Vanage, G., Marshall, A., Bardin, C.W. and Koide, S.S.
(1996): Anti-implantation activity of antiestrogens and mifepristone. Contraception, 54, 253-258.

Fuentealba, B., Nieto, M. and Croxatto, H.B. (1987): Ovum transport in pregnant rats is little affected by RU486 and exogenous progesterone as compared to cycling rats. Biol. Reprod., 37, 768-774.

Gao, Y. and Short, R.V. (1994): Fertility control in laboratory rats and mice after feeding with the antigestagen RU486. J. Reprod. Fertil., 101, 477-481.

Gemzell-Danielsson, K., Swahn, M-L., Westlund, P., Johannisson, E., Seppala, M. and Bygdeman, M. (1997): Effect of low daily doses of mifepristone on ovarian function and endometrial development. Hum. Reprod., 12, 124-131.

Gemzell-Danielsson, K. and Marions, L. (2004): Mechanisms of action of mifepristone and levonorgestrel when used for emergency contraception. Hum. Reprod., 10, 341-348.

Ledger, W.L., Sweeting, V.M., Hillier, H. and Barird, D.J. (1992): Inhibition of ovulation by low-dose mifepristone (RU 486). Hum. Reprod., 7, 945-950.

O'Connor, J.C., Davis, L.G., Frame, S.R. and Cook, J.C. (2000): Evaluation of a Tier I screening battery for detecting endocrineactive compounds (EACs) using the positive controls testosterone, coumestrol, progesterone, and RU486. Toxicol. Sci., 54, 338-354.

Pedersen, T. and Peters, H. (1968): Proposal for a classification of oocytes and follicles in the mouse ovary. J. Reprod. Fertil., 17, 555-557.

Psychoyos, A. and Prapas, I. (1987): Inhibition of egg development and implantation in rats after post-coital administration of the progesterone antagonist RU 486. J. Reprod. Fertil., 80, 487-491.

Rao, I.M. and Mahesh, V.B. (1986): Role of progesterone in the modulation of the preovulatory surge of gonadotropins and ovulation in the pregnant mare's serum gonadotropin- primed immature rat and the adult rat. Biol. Reprod., 35, 1154-1161.

Reel, J.R., Hild-Petito, S. and Blye, R.P. (1998): Antiovulatory and postcoital antifertility activity of the antiprogestin CDB-2914 when administered as single, multiple, or continuous doses to rats. Contraception, 58, 129-136.

Roblero, L.S., Fernández, O. and Croxatto, H.B. (1987): The effect of RU486 on transport, development and implantation of mouse embryos. Contraception, 36, 549-555.

Roblero, L.S. and Croxatto, H.B. (1991): Effect of RU486 on development and implantation of rat embryos. Mol. Reprod. Dev., 29, 342-346.

Rumpel, E., Michna, H. and Kühnel, W. (1993): Morphology of the rat uterus after long-term treatment with progesterone antagonists. Ann. Anat., 175, 141-149.

Sánchez-Criado, J.E., Bellido, C., Galiot, F., López, F.J. and Gaytán, F. (1990): A possible dual mechanism of the anovulatory action of antiprogesterone RU486 in the rat. Biol. Reprod., 42, 877886.

Sánchez-Criado, J.E., Sánchez, A., Ruiz, A. and Gaytán, F. (1993): Endocrine and morphological features of cystic ovarian condition in antiprogesterone RU486-treated rats. Acta. Endocrinol. (Copenh), 129, 237-245.

Sánchez-Criado, J.E., Ruiz, A., Tébar, M. and Mattheij, J.A. (1996): Follicular and luteal progesterone synergize to maintain 5-day cyclicity in rats. Rev. Esp. Fisiol., 52, 223-229.

Sitruk-Ware, R. (2006): Mifepristone and misoprostol sequential regimen side effects, complications and safety. Contraception., 74, 48-55.

Srivastava, U.K., Srivastava, S.R., Chowdhury, S.R. and Singh, 
M.M. (1995): Early abortifacient action of RU486 by continuous intravenous infusion in rat. Contraception, 51, 273-276.

Tebar, M., Ruiz, A., Gaytan, F. and Sánchez-Criado, J.E. (1995): Follicular and luteal progesterone play different roles synchronizing pituitary and ovarian events in the 4-day cyclic rat. Biol. Reprod., 53, 1183-1189.

Telleria, C.M. and Deis, R.P. (1996): Reproductive function in rats after mifepristone-induced termination of pregnancy. Contraception, 53, 185-190.

Telleria, C.M., Mezzadri, M.R. and Deis, R.P. (1997): Fertili- ty impairment after mifepristone treatment to rats at proestrus. Actions on the hypothalamic-hypophyseal-ovarian axis. Contraception, 56, 267-274.

van der Schoot, P., Bakker, G.H. and Klijn, J.G. (1987): Effects of the progesterone antagonist RU486 on ovarian activity in the rat. Endocrinology, 121, 1375-1382.

Yang, Y.Q. and Wu, J.T. (1990): RU 486 interferes with egg transport and retards the in vivo and in vitro development of mouse embryos. Contraception, 41, 551-556. 